\title{
Platinum(II) Complexes with Arginine and Histidine
}

\author{
Dale D. Nelson and Herschel Frye \\ University of the Pacific, Stockton, California \\ (Z. Naturforschg. 21 b, 630-632 [1966] ; eingegangen am 1. März 1966)
}

\begin{abstract}
Two new complexes of platinum(II) with alpha amino acids have been prepared and characterized; these are diaquobisarginatoplatinum(II) and diaquotrishistidinatodiplatinum(II) chloride. Efforts to prepare similar complexes with lysine and serine using similar synthetic techniques failed to produce separable compounds. Infrared data, analytical results for carbon and hydrogen, and melting point information support the structures postulated in this report; no success was achieved in determining molecular weight by the $\mathrm{R}$ a s $\mathrm{t}$ method.
\end{abstract}

The chelating tendencies of the alpha amino acids are well known and have been widely studied ${ }^{1-4}$. Platinum(II) furnishes an excellent metal cation for use in such studies because of its stability and known square planar coordination geometry. Complexes of platinum(II) have been reported with glutamic and aspartic acids ${ }^{5}$, alanine and tyrosine ${ }^{6}$, asparagine ${ }^{2}$, methionine ${ }^{3}$, and valine ${ }^{7}$ among others. Search of the literature finds no mention of platinum(II) complexes with arginine and histidine; however, a number of complexes with other metal cations and these basic amino acids have been reported. $\mathrm{Lr}$ and Doody ${ }^{8}$ have reported complexes of arginine with copper(II) and zinc(II), and Brigando ${ }^{9}$ has prepared a cobalt-arginine complex in which the amino acid behaved as a monodentate. Histidine complexes with zinc(II), nickel(II), cobalt (II), and copper(II) have been reported by Andrews and Zebolsky ${ }^{10}$, and SPEnce and LeE ${ }^{11}$ have studied the 1:1 histidine complex with molybdenum(VI). Histidine-copper(II) complexes have been further studied by ValladasDubois ${ }^{12}$, and Earnshaw and Larkworthy ${ }^{13}$ have indicated that histidine acts as a tridentate with cobalt (II).

This report concerns the successful syntheses of the arginine and histidine complexes of platinum(II). The methods used in establishing the formation of

1 J. Ballar, The Chemistry of the Coordination Compounds, Reinhold Publishing Company, New York 1956.

2 L. Volshtein and L. Anakhova, Zhur. Neorgan. Khim. 7, 11 [1962].

3 L. Volshtein and M. Mogilevkina, Doklady Akademii Nauk SSSR 142, 1305 [1962].

${ }^{4}$ L. Volshtein and M. Mogilevinina, Zhur. Neorgan. Khim. 8, 597 [1963].

5 A. Grinberg and R. Kats, Izvest. Sektora Platiny i Drug. Blagorod. Metal., Inst. Obschei i Neorg. Khim. Akad. Nauk SSSR 29, 37 [1955].

${ }^{6}$ L. Volshtein and N.Velikanova, Zhur. Neorgan. Khim. l, 48 [1956]. coordination complexes and in postulating their structures are primarily those of infrared absorption spectrophotometry and of elemental analyses for carbon and hydrogen coupled with ultraviolet-visible and other techniques. Details are described below for syntheses, characterizations, and establishment of structure.

\section{Synthesis of diaquobisarginatoplatinum(II)}

4.0 millimoles of reagent grade sodium tetrachloroplatinate(II) were dissolved in five milliliters of water which had been deoxygenated with nitrogen. The solution was filtered and placed in a fifty milliliter round flask fitted with a standard taper reflux condenser; nitrogen was bubbled through the solution for thirty minutes to remove all oxygen from the flask and its contents. 16.0 millimoles of reagent grade arginine dissolved in twenty milliliters of nitrogen-treated water were added to the reaction flask, and the mixture was heated on an oil bath at a temperature of $95{ }^{\circ} \mathrm{C}$. for twelve hours; nitrogen was bubbled through the reacting solution at a constant rate throughout the period.

The color of the mixture changed from dark red to nearly colorless during the course of the reaction, and no further color change as measured with a Beckman DB spectrophotometer was interpreted as reaction completion. The flask was removed from the oil bath and allowed to cool to room temperature still under nitrogen. The $p_{\mathrm{H}}$ change during the course of reaction was from 11.0 to 9.5 .

${ }^{7}$ L. Volshtein and G. Zegzhda, Zhur. Neorgan. Khim. 7, 11 [1962].

8 N. Li and E. Doody, J. Amer. chem. Soc. 76, 221 [1954].

9 C. Terlon and J. Bragando, C. R. hebd. Séances Acad. Sci. 253, 2069 [1961].

10 A. Andrews and D. Zebolsky, J. chem. Soc. [London] 1965,142

11 J. Spence and J. Lee, Inorg. Chem. 4, 385 [1965].

12 S. Valladas-Dubois, Bull. Soc. Chim. biol. 1961, 967.

13 A. Earnshaw and L. Larkworthy, Nature [London] 192, 4807 [1961]. 
The stoppered flask - still under nitrogen - was placed in an ice bath; after twelve days, a fine white precipitate formed which was filtered and washed with ice water. The yield was 10 per cent and the melting point was sharp at $210^{\circ} \mathrm{C}$.

\section{Characterization of diaquobisarginatoplatinum(II)}

Carbon and hydrogen data are reported in Table I; these are somewhat high because of some coprecipitated free acid and some occluded water. Small yields did not permit intensive recrystallization.

\begin{tabular}{|ccc|cc|}
\hline \multicolumn{2}{|c|}{ Theoretical } & \multicolumn{2}{c|}{ Reported } \\
Carbon & Hydrogen & Carbon & Hydrogen \\
\hline 25.1 & 5.25 & 25.7 & 6.28 \\
\hline
\end{tabular}

Table 1. Carbon-hydrogen data for the platinum(II) complex of arginine.

These data fit best a structure in which two molecules of water are coordinated at trans-square planar positions; thus arginine acts as a monodentate, and doubtless the nitrogen of the amino group is the donor rather than the carboxyl oxygen.

Infrared data substantiate the structure proposed above. Table II shows that there was significant change in the region attributed to $\mathrm{N}-\mathrm{H}$ stretch at $3000 \mathrm{~cm}^{-1}$, but none in the $1670 \mathrm{~cm}^{-1}$ region attributed to $\mathrm{COO}^{-}$.

\begin{tabular}{|l|rrrrr|}
\hline \multicolumn{1}{|c|}{ Compound } & \multicolumn{5}{|c|}{ Principal absorption peaks, $\mathrm{cm}^{-1}$} \\
\hline Arginine & 3220 & 3200 & 1670 & 1610 & 1545 \\
$\mathrm{Pt}(\mathrm{II})$ complex & 3200 & 3100 & 1670 & 1625 & 1530 \\
\hline
\end{tabular}

Table II. Principal infrared data for the platinum(II) complex of arginine.

The proposed geometry results in a neutral species, and the negative test for chloride ion validates this conclusion in view of the presence of that anion in the reacting mixture. On the basis of all information (including ultravioletvisible), we propose the following structure for the complex:

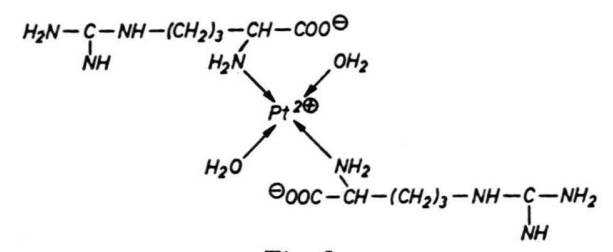

Fig. 1.
Other structures are possible, and indeed may contribute, but all evidence indicates the proposed structure is best. Also, Grinberg and Kats ${ }^{14}$ report similar restults for the reaction of potassium tetrachloroplatinate(II) and aspartic acid.

\section{Synthesis of diaquotrishistidinatodiplatinum(II) chloride}

3.78 millimoles of reagent grade sodium tetrachloroplatinate(II) were dissolved in eight milliliters of nitrogen-treated water, and the solution was placed in the previously described apparatus. 7.56 millimoles of reagent grade histidine dissolved in 34 milliliters of nitrogen-treated water were added, the system was flushed with nitrogen, and the flask was placed on the oil bath at $95{ }^{\circ} \mathrm{C}$. Reaction began within an hour as evidenced by a change in color from deep red-brown to brown containing a flocculent light colored precipitate. After four hours, the reaction was complete and the flask and contents were cooled and packed in crushed ice for six hours. The mixture was then filtered and washed four times with small amounts of ice water.

The solid was dissolved in sixty milliliters of cold water, and the solution was filtered to remove a very small amount of gray residue assumed to be platinum or platinum oxide. The solution was then carefully evaporated on a hot plate at low temperature under nitrogen to a volume of ten milliliters. Cooling to $0{ }^{\circ} \mathrm{C}$. in an ice bath yielded light brown crystals which were removed by filtration, washed sparingly in ice water, and dried over anhydrous calcium chloride. The yield was seventeen per cent of theoretical; the melting point using a Thomas Hoover Capillary apparatus was $340{ }^{\circ} \mathrm{C}$. with decomposition.

\section{Characterization of diaquotrishistidinato- diplatinum(II) chloride}

A solution of the crystals gave a positive test for chloride ion and thus evidence to support the proposed cationic structure. The carbon-hydrogen data as reported in Table III substantiate the structure proposed below.

\begin{tabular}{|cc|cc|}
\hline \multicolumn{2}{|c|}{ Theoretical } & \multicolumn{2}{c|}{ Reported } \\
Carbon & Hydrogen & Carbon & Hydrogen \\
\hline 22.52 & 3.36 & 22.80 & 3.48 \\
\hline
\end{tabular}

Table III. Carbon-hydrogen data for the platinum(II) complex of histidine.

Slightly high values again may be attributed to the inclusion of small amounts of the free acid.

14 A. Grinberg and R. Kats (see number 5 above). 
The infrared data in Table IV indicate that coordination is via nitrogen and not via carboxyl groups.

\begin{tabular}{|l|rrrrrr|}
\hline Compound & \multicolumn{6}{c|}{ Principal absorption peaks, $\mathrm{cm}^{-1}$} \\
\hline $\begin{array}{l}\text { Histidine } \\
\begin{array}{l}\text { Pt(II) } \\
\text { complex }\end{array}\end{array}$ & 2920 & 2800 & 2640 & 1610 & 1570 & 1550 \\
\hline
\end{tabular}

Table IV. Principal infrared data for the platinum(II) complex of histidine.

These data, as well as those from ultraviolet-visible spectrophotometry, point to a structure in which there are two platinum(II) ions, three histidinate ions, and two water molecules. We propose that one histidinate ion acts as a bridge between two platinum ions utilizing and amino nitrogen and the number one nitrogen of the imidazole ring. The other histidinate ions behave as bidentates using these same nitrogen atoms for chelation. This structure may be represented as follows:

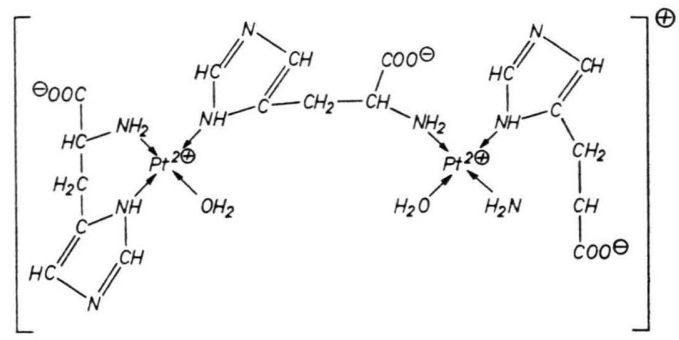

Fig. 2. Proposed Structure of Histidine Complex of Platinum (II).

\title{
Strahlenchemische Erzeugung und optische Absorptionsspektren organischer Schwefelradikale in organischen Gläsern bei $-196{ }^{\circ} \mathrm{C}$
}

\author{
J. Wendenburg, H. Möckel, A. Granzow und A. Henglein \\ Hahn-Meitner-Institut für Kernforschung Berlin, Sektor Strahlenchemie, Berlin-Wannsee
}

(Z. Naturforschg. 21 b, 632-642 [1966] ; eingegangen am 19. März 1966)

\begin{abstract}
Organic disulfides, mercaptans, sulfides and hydrogen sulfide have been exposed to $\gamma$-radiation in glasses of methyltetrahydrofuran or hydrocarbons at $-196{ }^{\circ} \mathrm{C}$. Absorptions have been observed which are attributed to either radicals of the type RS - or to addition complexes of these radicals to S-containing molecules or ions (for example to $\mathrm{RS}-\mathrm{SR}^{-}$radical ions). In the case of disulfides. the S-radicals were produced by dissociative capture of electrons from the ionization of the glassy solvent. In the case of mercaptans, the sulphur radicals were formed via H-abstraction by free radicals from the radiolysis of the solvent, when the irradiated glasses were slowly warmed up. HS was formed this way in $\mathrm{H}_{2} \mathrm{~S}$ containing irradiated glasses. The electron capture in benzylmercaptan, dibenzyldisulfide, and dibenzylsulfide partially leads to the benzylradical. Several new absorption bands have been observed which are tentatively attributed to negative ions: $\mathrm{C}_{6} \mathrm{H}_{5} \mathrm{SH}^{\ominus}$ from phenylmercaptan $(8100 \AA), \mathrm{C}_{6} \mathrm{H}_{5} \mathrm{SC}_{6} \mathrm{H}_{5} \ominus$ from diphenylsulfide (broad absorption over the visible range), $\mathrm{C}_{6} \mathrm{H}_{5} \mathrm{CHS} \odot$ from dibenzylsulfide $(\sim 3900 \AA)$. Carbontetrachloride simultaneously present in the glass was found to inhibit all reactions of free electrons, while the reactions of free radicals during warming up were not suppressed.

Glasses of a methylcyclohexane-isopentane mixture containing olefins were found to absorb strongly between 7000 and $9000 \AA$. These absorptions are attributed to positive ions. The absorption of ionized or protonated olefins occurs at longer wave lengths with decreasing number of $\mathrm{H}$-atoms at the carbon atoms of the double bond. Absorption by positive ions was also observed for diphenyldisulfide $(8500 \AA)$, and for diallyldisulfide $(6840 \AA)$. Small amounts of substances which can readily be protonated (such as n-propanol or methyltetrahydrofuran) decrease the intensity of the absorption bands of positive ions.
\end{abstract}

Organische Schwefelradikale vom Typ HR-S · $(\mathrm{HR}=$ organischer Rest) sind bisher nur wenig untersucht worden. In röntgenbestrahltem Cystin hat man das Radikal $\mathrm{HOOC}-\mathrm{CH}\left(\mathrm{NH}_{2}\right) \mathrm{CH}_{2} \mathrm{~S}$ durch Elektronenspinresonanz-Absorption nachgewiesen ${ }^{1}$. ESR-Messungen sind auch an $\gamma$-bestrahlten Alkyldisulfiden in amorphem Zustand und in Me-

\footnotetext{
1 Y. Kurita u. W. Gordy, J. chem. Physics 34, 282 [1961].
}

thyltetrahydrofuran-Glas bei tiefer Temperatur durchgeführt worden; die erhaltenen ESR-Spektren wurden so gedeutet, daß hauptsächlich positive und negative Ionen der Disulfide gebildet werden, während Schwefelradikale und Kohlenstoffradikale nur in kleinen Mengen vorhanden sind ${ }^{2}$. In bestrahltem Phenyl- und Benzyldisulfid sowie in Mercapta-

\footnotetext{
2 F. K. Truby, J. chem. Physics 36, 2227 [1962] ; 40, 2768 [1964].
} 